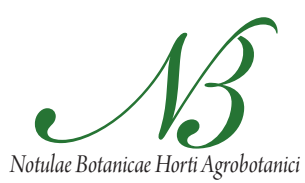

Cluj-Napoca

\title{
Tocopherol Content in Vegetable Oils Using a Rapid HPLC Fluorescence Detection Method
}

\author{
Constantin BELE, Cristian T.MATEA*, Camelia RADUCU, Vioara MIRESAN, Octavian NEGREA \\ University of Agricultural Sciences and Veterinary Medicine Cluj-Napoca, 3-5 Manastur Street, 400372 \\ Cluj-Napoca, Romania; cristian.matea@usamvcluj.ro (* correspondingauthor)
}

\begin{abstract}
A quick and direct method based on reversed phase high performance liquid chromatography with fluorescence detector for measuring tocopherols $(\alpha, \beta+\gamma$ and $\delta)$ has been developed. Oils are diluted in methanol: hexane: tetrahydrofuran (neither previous extraction of tocopherols nor saponification procedure are required) and after being vortexed and centrifuged, an aliquot of the overlay was injected directly into an Alltima C 18 column. Acetonitrile and methanol (50:50) mixture was used as a mobile phase with a flow rate of $1 \mathrm{~mL} \mathrm{~min}^{-1}$. Quantification of tocopherols was performed by fluorescence detector at $290 \mathrm{~nm}$ excitation wavelength and $325 \mathrm{~nm}$ emission wavelength. Tocopherols were separated at $25^{\circ} \mathrm{C}$ in less than $10 \mathrm{~min}$ after injection. The method has good limit of detection $(9$ $\mathrm{ng} \mathrm{g}^{-1}$ for $\alpha$-tocopherol and $8 \mathrm{ng} \mathrm{g}^{-1}$ for $\beta$-, $\gamma$ - and $\delta$-tocopherols) and reproducibility $(\mathrm{CV}<2.9 \%)$. This method can be used to assess the influence of genetic modification of oil seeds on the distribution of tocopherols or the effect of tocopherols on the oxidative stability of edible plant oils.
\end{abstract}

Keywords: food analysis, oils, RP-HPLC, tocopherols

\section{Introduction}

Vegetable oils are probably the major dietary source of vitamin $\mathrm{E}$ (Hammond, 2003), with a variable isomer profile according to the oil identity (Amaral et al., 2005). Tocopherols protect food from oxidation by protecting the stability of oils and fats (Tangolar et al., 2011). Tocopherols are a group of fat soluble antioxidants with a chromanol ring and a hydrophobic side chain and exist in four different congeners (vitamers) called alpha, beta, gamma and delta, which differ in the methylation pattern of the benzopyran ring (Boschin and Arnoldi, 2011; Schwarz et al., 2008). Alpha tocopherol has three methyl groups, beta and gamma forms have two methyl groups and the delta has one methyl group. The biological activities of these compounds are mainly attributed to their radical-chainbreaking antioxidant in membranes and lipoproteins, as well as in foods (Kamal-Eldin and Appelqvist, 1996). The most active form of vitamin $\mathrm{E}$ is $\alpha$-tocopherol which is believed to protect the body against degenerative malfunction, particularly cancer and cardiovascular disease (Hasani et al., 2008; Zingg, 2007). $\gamma$-Tocopherol has been reported to be more potent than $\alpha$-tocopherol in decreasing platelet aggregation, delaying intra-arterial thrombus aggregation and LDL oxidation (Li et al., 1999; Saldeen et al., 1999).

Several methods have been described for the analysis of tocopherols by gas chromatography (GC) and high performance liquid chromatography (HPLC) (Habib et al., 2013; Lee et al., 2012; Slavin and Yu 2012). Analysis of tocopherols in vegetable oils by HPLC can employ either normal- or reversed phase columns, as well in isocratic as in gradient elution, with fluorescent, electrochemical and UV detection (Jedlicka and Klimes, 2005). The normal phase columns provide separation of all tocopherols, while reversed phase columns (usually C18) are unable to separate the $\beta$ - and $\gamma$-tocopherols (Andres et al., 2011). RPHPLC is preferred over normal-phase systems due to the reproducibility of retention times, fast equilibration, and robustness of reversed-phase columns over other stationary phases (Cert et al., 2000). When the separation of $\beta$ - and $\gamma$-tocopherols is not the point of analysis, reversed phase columns are preferred (Gliszczynska-Swiglo and Sikorska, 2004). Fluorescence detection permits to get lower detection limits (Gimeno et al., 2000).

In this work we optimized a quick and simple method for routine analysis of tocopherols in vegetable oils by RPHPLC with fluorescence detection. The oil was diluted in methanol / hexane/ tetrahydrofuran and after being vortexed and centrifuged, an aliquot of the overlay was injected directly into an Alltima C18 column.

\section{Materials and methods}

\section{Reagents and standard solutions}

Acetonitrile, methanol, tetrahydrofuran and hexane were HPLC grade and were purchased from Merck (Darmstadt, Germany). $\alpha-, \beta-, \gamma$ - and $\delta$-Tocopherols standards were obtained from Calbiochem (Merck Biosciences, Darmstadt, Germany). Standard stock solutions of 
94

tocopherols were prepared in ethanol and stored at $-20^{\circ} \mathrm{C}$ in dark bottles for up to a month. The exact concentrations were determined spectrophotometrically (Ryynanen et al., 2004). Working standard solutions of analytes were prepared from these solutions directly before analysis.

\section{High-performance liquid chromatography (HPLC)}

Separation by HPLC was carried out using a Shimadzu liquid chromatograph system equipped with two delivery pumps (LC-10 AD), a FL detector (FR-10 AXL), a degasser and a model $7725 \mathrm{i}$ manual injector valve with a $20 \mathrm{ul}$ sample loop. The column was an Alltima RP C-18 $(250 \times 4.6 \mathrm{~mm}, 5 \mu \mathrm{m}$, Alltech Associates Inc.).

The mobile phase was a mixture of acetonitrile and methanol (50:50,v/v) and eluted at a flow rate of $1.0 \mathrm{~mL}$ $\mathrm{min}^{-1}$. The analytical column was kept at $25^{\circ} \mathrm{C}$. The fluorescence detector was set at $290 \mathrm{~nm}$ excitation wavelength and $325 \mathrm{~nm}$ emission wavelength. The total separation time was $10 \mathrm{~min}$. The injection volume was $20 \mu \mathrm{L}$. The tocopherols were identified by comparison of the retention times with standards of the $\alpha-, \beta$-, $\gamma$ - and $\delta$-tocopherols.

\section{Tocopherols quantification}

An external calibration was performed prior to analyses of edible plant oils, by injecting different volumes $(10$ and $20 \mu \mathrm{L})$ of tocopherol working solutions $\left(0.2-5 \mathrm{mg} \mathrm{L}^{-1}\right)$ on column. Standard curves (concentration versus peak area) were calculated by linear regression analysis. Injections in triplicate were made at each concentration for both standards and samples. The calibration curves were constructed using standard solutions of $\alpha$-, $\beta$-, $\gamma$ - and $\delta$-tocopherol and used for quantification. The total tocopherol content is expressed as milligrams per gram oil.

\section{Sample preparation}

Corn, walnut, grape seed, rice, virgin olive, sesame, peanut, sunflower oils were purchased in a local market. The samples were stored in the dark at $(21 \pm 2)^{\circ} \mathrm{C}$ until

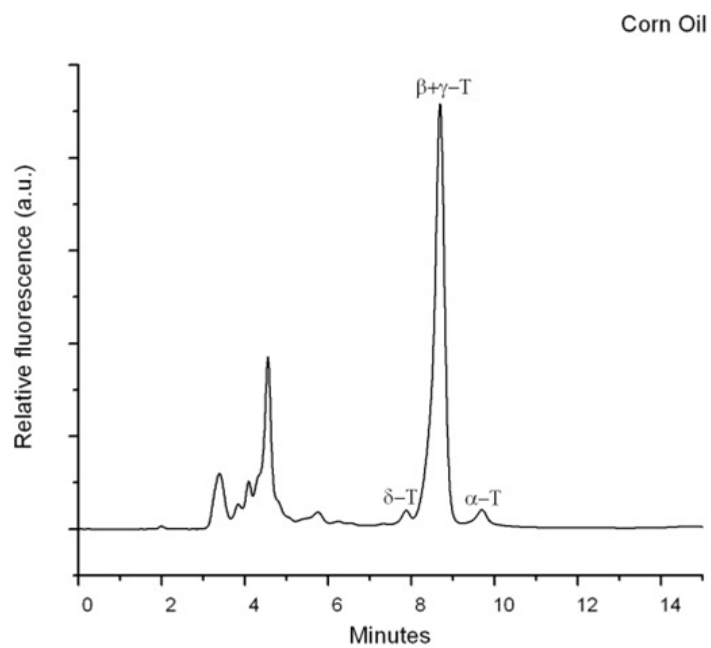

the measurements were performed. Pure oil samples were weighted (about $50 \mathrm{mg}$ ) and diluted 10 times in hexane. Thereafter, $50 \mu \mathrm{L}$ of above solution was taken into a screwcapped tube and diluted with $1 \mathrm{~mL}$ of a mixture of methanol: hexane: tetrahydrofuran $(80: 10: 10, \mathrm{v} / \mathrm{v} / \mathrm{v})$. The sample was vortexed for $5 \mathrm{~min}$ and centrifuged for $10 \mathrm{~min}$. at $5000 \mathrm{rpm}$. After that, the sample was filtered through a $0.45 \mu \mathrm{m}$ pore size filter and an aliquot of the clear liquid was directly injected into HPLC column.

\section{Results and discussion}

\section{Method assessment and validation}

Typical chromatograms obtained for the oils tested are presented below (Fig .1). A good resolution and acceptable retention times were obtained. Tocopherols were further identified by comparing retention times with those of authentic standards. The retention times of $\delta$-, $(\beta+\gamma)$ - and $\alpha$-tocopherols were about $7.85 \mathrm{~min}, 8.65 \mathrm{~min}$ and 9.72 min., respectively and were determined from their authentic standards which were injected both individually and as a mixture. The analysis time is lower than found in the literature (Breithaupt and Kraut, 2006; Delgado-Zanarreno et al., 2006; Kuhn et al., 2008). Similar results were found by other authors with different protocols for sample preparation and HPLC separation of tocopherols (Chen et al., 2011; Gliszczynska-Swiglo and Sikorska, 2004).

Validation results are summarized in Tab. 1. Calibration curves ( $\mathrm{n}=8$ points) were linear between $0.05-10 \mu \mathrm{g}$ $\mathrm{g}^{-1}$. Linear correlation coefficient $(\mathrm{r})$ for all standard curves were not lower than 0.995 . The reproducibility of the analysis (sample dilution, injection and chromatographic run) was measured by $C V \%$ of $\alpha$ - and $(\beta+\gamma)$-tocopherol (Chen et al., 2011) in three replicates of olive oil and of $\delta$-tocopherol in three replicates of walnut oil. Accuracy was tested by the standard addition procedure (\% of recovery). The standard mixture was added to aliquots of grape seed oil at three concentration levels ( $n=3$ replicates). The

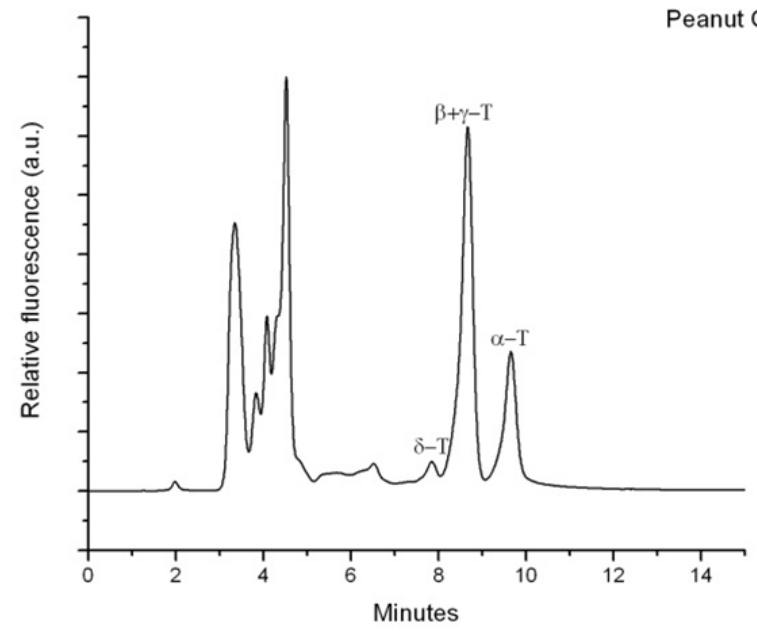

Fig. 1. Typical chromatograms of corn and peanut oils 
results demonstrate good recovery for the tocopherols (ranging from $97.5 \%$ to $101.0 \%$ ). The limits of detection (LOD) calculated as the concentration corresponding to three times the standard deviation of the baseline noise were not higher than $9 \mathrm{ng} \mathrm{mL}^{-1}$. The limits of quantification (LOQ) were investigated by sample dilution and were not higher than $28 \mathrm{ng} \mathrm{mL}^{-1}$.

\section{Quantification of tocopherols in edible plant oils}

The distribution of individual tocopherols and their total content in assessed oils are reported in Tab. 2. All values are arithmetic mean of at least three separate determinations.

$\alpha$-Tocopherol dominates in olive, grape seed, peanut and sunflower oils. In corn, walnut and sesame oils $(\beta+\gamma)$ tocopherols dominate. The concentration of $\delta$-tocopherol in all oils is not higher than $0.032 \mathrm{mg} \mathrm{g}^{-1}$. $\alpha$-Tocopherol is absent in sesame oil and $\delta$-tocopherol in olive oil. The results obtained are generally in agreement with the literature data (Berasategi et al., 2012; Rammell and Hoogenboom, 1985; Sanchez-Perez et al., 2000). Lack of separation of $\beta$ - and $\gamma$-tocopherols in the case of edible oils introduce rather small error in quantification of these isomers (Gliszczynska-Swiglo and Sikorska, 2004). This is because, according to literature (Crawley, 1993; Gregory, 1996) plant oils contain small quantities of $\beta$-tocopherol as compared with $\gamma$-tocopherol. When necessary, all to- copherols can be fully separated using normal phase chromatography.

\section{Conclusions}

This study presents a simple, fast and precise method for determination of tocopherols in edible oils. The method proposed a new fast sample preparation which avoids quantification errors (dilution of the oil in methanol/hexane/tetrahydrofuran mixture, no saponification procedures, then the sample was vortexed-mixed and centrifuged), direct injection of the overlay in a low-cost RP- HPLC column and is based on a high sensitivity and selectivity of the fluorimetric detector. Tocopherols can preserve their stability by using the protocol proposed for sample preparation. Lack of separation of $\beta$ - and $\gamma$ - tocopherols by RP-HPLC did not introduce major error in the determination of latter one because vegetable oils contain small quantities of $\beta$ - tocopherol as compared to $\gamma$ tocopherol. Therefore, the method proposed can be useful for the routine analysis of $\alpha-,(\beta+\gamma)$ - and $\delta$ - tocopherols in edible vegetable oils and is comparable only to a few published methods (Chen et al., 2011; Gliszczynska-Swiglo and Sikorska, 2004). This method can be used to assess the influence of genetic modification of oil seeds on the distribution of tocopherols or the effect of tocopherols on the oxidative stability of edible plant oils.

Tab. 1. Method validation parameters for determination of tocopherols in edible plant oils

\begin{tabular}{ccccc}
\hline Parameter & $\begin{array}{c}\alpha \text {-Tocopherol } \\
\mathrm{t}_{\mathrm{R}}=9.72 \pm 0.1 \mathrm{~min}\end{array}$ & $\begin{array}{c}\beta \text {-Tocopherol } \\
\mathrm{t}_{\mathrm{R}}=8.65 \pm 0.1 \mathrm{~min}\end{array}$ & $\begin{array}{c}\gamma \text {-Tocopherol } \\
\mathrm{t}_{\mathrm{R}}=8.65 \pm 0.1 \mathrm{~min}\end{array}$ & $\begin{array}{c}\delta \text {-Tocopherol } \\
\mathrm{t}_{\mathrm{R}}=7.85 \pm 0.1 \mathrm{~min}\end{array}$ \\
\hline Range $\left(\mathrm{\mu g} \mathrm{g}^{-1}\right)$ & $0.05-10$ & Standard linearity & $0.05-10$ & $0.95-10$ \\
$\mathrm{R}^{2}$ & 0.9956 & $0.05-10$ & 0.9974 & $2.3 \%$ \\
\hline Precision $(\mathrm{CV} \%)(\mathrm{N}=3)$ & $1.6 \%$ & 0.9967 & $2.7 \%$ & 8 \\
\hline LOD $\left(\mathrm{ng} \mathrm{g}^{-1}\right)^{\mathrm{a}}$ & 9 & $2.9 \%$ & 8 & 23 \\
\hline LOQ $\left(\mathrm{ng} \mathrm{g}^{-1}\right)^{\mathrm{b}}$ & 28 & Sensitivity & 23 & 101.0 \\
\hline
\end{tabular}

${ }^{a}$ Calculated based on a $\mathrm{S} / \mathrm{N}$ ratio of three.

${ }^{\mathrm{b}}$ Calculated as $3 \mathrm{x}$ LOD

Tab. 2. Distribution of $\alpha-,(\beta+\gamma)-, \delta$ - tocopherols and total tocopherol content in assessed oils

\begin{tabular}{ccccc}
\hline Oil sample & $\begin{array}{c}\alpha \text {-Tocopherol } \\
(\mathrm{mg} \text { per 100g) }\end{array}$ & $\begin{array}{c}(\beta+\gamma) \text {-Tocopherols } \\
(\mathrm{mg} \text { per 100g })\end{array}$ & $\begin{array}{c}\delta \text {-Tocopherol } \\
(\mathrm{mg} \text { per 100g })\end{array}$ & $\begin{array}{c}\text { Total Tocopherols } \\
(\mathrm{mg} \text { per 100g) }\end{array}$ \\
\hline Olive & $19.53 \pm 0.1$ & $0.91 \pm 0.01$ & - & 20.44 \\
Grape seed & $12.45 \pm 0.01$ & $2.14 \pm 0.01$ & $0.71 \pm 0.04$ & 15.3 \\
Corn & $5.60 \pm 0.02$ & $41.12 \pm 0.4$ & $1.82 \pm 0.04$ & 48.54 \\
Walnut & $1.47 \pm 0.01$ & $19.13 \pm 0.07$ & $3.23 \pm 0.04$ & 23.83 \\
Sesame & - & $29.37 \pm 0.4$ & $0.57 \pm 0.07$ & 29.84 \\
Peanut & $19.22 \pm 0.2$ & $9.32 \pm 0.2$ & $0.91 \pm 0.03$ & 29.45 \\
Rice & $3.31 \pm 0.05$ & $3.56 \pm 0.03$ & $0.62 \pm 0.05$ & 7.49 \\
Sunflower & $73.02 \pm 0.3$ & $1.98 \pm 0.06$ & $0.82 \pm 0.04$ & 75.82 \\
\hline
\end{tabular}

Data are calculated from three replicated analysis of each sample \pm SD 
96

\section{Acknowledgements}

This work was partially financed by grant USAMV-CJ RU no. 1283/2013. The authors acknowledge the support of the Society for Interdisciplinary Applicative Research.

\section{References}

Amaral JS, Casal S, Torres S, Seabra D, Oliveira BPP (2005). Simultaneous determination of tocopherols and tocotrienols in hazelnuts by a normal phase chromatographic method. Analyt Sci 21:1545-1548.

Andres MPS, Otero J, Vera S (2011). High performance liquid chromatography method for the simultaneous determination of $\alpha-, \gamma$ - and $\delta$ - tocopherol in vegetable oils in presence of hexadecyltrimethylammonium bromide/n-propanol in mobile phase. Food Chem 126:1470-1474.

Berasategi I, Barriuso B, Ansorena D, Astiasaran I (2012). Stability of avocado oil during heating: Comparative study to olive oil. Food Chem 132:439-446.

Boschin G, Arnoldi A (2011). Legumes are valuable sources of tocopherols. Food Chem 127:1199-1203 .

Breithaupt DE, Kraut S (2006). Simultaneous determination of the vitamins A, E, their esters and coenzymes Q 10 in multivitamin dietary supplements using an RP-C30 phase. European Food Res Technol 222:643-649.

Cert A, Moreda W, Perez-Camino MC (2000). Chromatographic analysis of minor constituents in vegetable oils. J Chromatog A 881:131-148.

Chen H, Angiuli M, Ferrari C, Tombari E, Salvetti G, Bramanti $\mathrm{E}$ (2011). Tocopherol speciation as first screening for the assessement of extra virgin olive oil quality by reversed-phase high- performance liquid chromatography/fluorescence detector. Food Chem 125:1423-1429.

Crawley H (1993). Natural occurrence of vitamin in food. In: Ottaway PB (Ed.). The Technology of Vitamins in Food. Chapman \& Hall, U.K.

Delgado-Zanarreno MM, Bustamande-Rangel M, Garcia-Jimenez M, Perez MS, Martinez RC (2006). Off-line coupling of pressurized liquid extraction and LC / ED for the determination of retinyl acetate and tocopherols in infant formulas. Talanta 70:1094-1099.

Gimeno E, Castelotte AI, Lamuela-Raventos RM, Torre MC, Lopez-Sabater MC (2000). Rapid determination of vitamin $\mathrm{E}$ in vegetable oils by reversed-phase high-performance liquid chromatography. J Chromatog A 881:251-254.

Gliszczynska-Swiglo A, Sikorska E (2004). Simple reversedphase chromatography method for determination of tocopherols in edible oils. J Chromatog A 1048:195-198.

Gregory JF (1996). Vitamins. In: Fennema OR (Ed.). Food Chemistry. Marcel Dekker, New York, Basel, Hong Kong.

Habib H, Kamal H, Ibrahim WS, Dhaheri ASA (2013).Carotenoids, fat soluble vitamins and fatty acid profiles of 18 varieties of date seed oil. Ind Crops Prod 42:567-572.

Hammond EW (2003). Vegetables and oils- composition and analysis, 5916-5921 p. In: Caballero B, Trugo LC, Finglas
PM (Eds.). Encyclopedia of Food Sciences and Nutrition, Elsevier Science Ltd.

Hasani NA, Yussof PA, Khalid BAK, Ghapor MTA, Ngah WZW (2008). The possible mechanism of action of palm oil gamma-tocotrienol and alpha-tocopherol on the cervical carcinoma caski cell apoptosis. Biomed Res -India 19:194200.

Jedlicka A, Klimes J (2005). Determination of water- and fatsoluble vitamins in different matrices using high performance liquid chromatography. Chem Pap 59:202-222.

Kamal-Eldin A, Appelqvist LA (1996). The chemistry and antioxidant properties of tocopherols and tocotrienols. Lipids 31:671-701

Kuhn M, Nakib S, Bandt JBd, Cynober L, Loi C (2008). Simultaneous determination of retinol and $\alpha$-tocopherol in polymeric diets for enteral nutrition. J Chromatog A 1205:186190.

Lee YY, Park HI, Lee CK, Kim SL, Hwang TY, Choi MS, Kwon YU, Kim WH, Lee SC, Kim YH (2012).Comparing extraction methods for the determination of tocopherols and tocotrienols in seeds and germinating seeds of soybean transformed with $O s H G G T$. J Food Comp Anal 27:70-80.

Li D, Saldeen T, Romeo F, Mehta JL (1999). Relative effects of alpha- and gamma-tocopherol on low-density lipoprotein oxidation and superoxide dismutase and nitric oxide synthase activity and protein expression in rats. J Cardiov Pharmacol Therapeu 4:219-226.

Rammell CG, Hoogenboom JJL (1985). Separation of tocol by HPLC on an amino-cyano polar phase column. J Liquid Chromatog Related Technol 8:707-717.

Ryynanen M, Lampi AM, Salo-Vaananen P, Ollilainen V, Piironen V (2004). A small- scale sample method with HPLC analysis for determination of tocopherols and tocotrienols in cereals. J Food Comp Anal 17:749-765.

Saldeen T, Li D, Mehta JL (1999). Differential effects of alphaand gamma - tocopherol on low-density lipoprotein oxidation, superoxide activity, platelet aggregation and arterial thrombogenesis. J Amer Coll Cardiol 34:1208-1215.

Sanchez-Perez A, Delgado-Zamarreno M, Bustamante-Rangel M, Hernandez-Mendez J (2000). Automated analysis of vitamin $\mathrm{E}$ isomers in vegetable oils by continuous membrane extraction and liquid chromatography-electrochemical detection. J Chromatog A 881:229-241.

Schwarz H, Ollilainen V, Piironen V, Lampi A-M (2008). Tocopherol, tocotrienol and plant sterol contents of vegetable oils and industrial fats. J Food Comp Anal 21:152-161.

Slavin M, Yu L (2012). A single extraction and HPLC procedure for simultaneous analysis of phytosterols, tocopherols and lutein in soybeans. Food Chem 135:2789-2795.

Tangolar SG, Ozogul F, Tangolar S, Yagmur C ( 2011). Tocopherol content in fifteen grape varieties obtained using a rapid HPLC method. J Food Comp and Anal 24:481-486.

Zingg JM (2007). Modulation of signal transduction by vitamin E. Mol Aspect Med 28:481-506. 